\title{
FENOMENA PERUBAHAN DALAM PELESTARIAN BUDAYA MESATUA BALI
}

\author{
I Gede Yudha Pratama \\ Program Studi Desain Komunikasi Visual, Institut Desain \& Bisnis Bali \\ Jl. Tukad Batanghari No. 29 Panjer Denpasar - Bali 80225 \\ Email : yudha.pratama@std-bali.ac.id
}

\begin{abstract}
Any change can occur when the rapid development of technology and information, which makes everything, including culture, must be able to co-exist with technology. Seeing the decline in Mesatua culture in Bali, the Mesatua tradition in Balinese society seems almost extinct. This can make a possibility for the loss of traditional culture which has cultural values that are very important for children. However, with the efforts to preserve culture through the use of digital media technology. Mesatua Bali, which was originally known as oral culture, is now becoming known as an image culture that is poured into digital media with interesting picture stories for children. To meet the data requirements used as research material, a descriptive qualitative research method is used to describe the phenomenon of change that occurs based on data collection through observation, documentation and literature study. The Mesatua Balinese culture in its preservation experiences a phenomenon of change in 3 periods, namely; oral period, writing period, and drawing period. In the phenomenon of change, each period has an impact or aspect of phenomena that causes new phenomena, changing phenomena, permanent phenomena, and even a phenomenon that is missing in the development of efforts to preserve Mesatua Bali culture.
\end{abstract}

Keywords: Fenomena Perubahan, Pelestarian, Budaya, Mesatua Bali, Cerita Bergambar

\begin{abstract}
ABSTRAK
Perubahan apapun dapat terjadi disaat pesatnya berkembangan teknologi dan informasi, yang membuat semua hal termasuk budaya harus mampu berdampingan dengan teknologi. Melihat surutnya budaya Mesatua di Bali membuat tradisi Mesatua dalam masyarakat Bali seakan hampir punah. Hal ini dapat membuat suatu kemungkinan hilangnya budaya tradisonal yang memiliki nilai-nilai budaya yang sangat penting bagi anak-anak. Namun, dengan adanya upaya pelestarian budaya melalui pemanfaatan teknologi media digital. Mesatua Bali yang mulanya dikenal sebagai budaya lisan sekarang mulai dikenal sebagai budaya gambar yang di tuangkan kedalam media digital dengan cerita bergambar yang menarik bagi anak-anak. Untuk memenuhi kebutuhan data yang digunakan sebagai bahan penelitian ini digunakan metode penelitian kualitatif deskriptif untuk mendeskripsikan fenomena perubahan yang terjadi dengan didasari atas pengumpulan data yang di lakukan melalui observasi, dokumentasi serta studi pustaka. Budaya Mesatua Bali dalam pelestariannya mengalami fenomena perubahan dalam 3 periode yaitu; periode lisan, periode tulisan, dan periode gambar. Dalam fenomena perubahan disetiap periodenya tersebut memiliki dampak atau aspek fenomena yang menimbulkan fenomena yang baru, fenomena berubah, fenomena yang tetap, dan bahkan ada suatu fenomena yang hilang dalam perkembangan upaya pelestarian budaya Mesatua Bali.
\end{abstract}

Kata Kunci: Fenomena Perubahan, Budaya, Mesatua Bali, Cerita Bergambar 


\section{Pendahuluan}

Bali memiliki kekayaan budaya luar biasa dan mempunyai masyarakat eksotis yang sangat berbakat dimata orang luar. Bali menyimpan ciri khas dan dinamis yang menunjukkan kekuatan agresif untuk berubah dan berkembang. Perubahan apapun dapat terjadi disaat pesatnya berkembangan teknologi dan informasi, yang membuat semua hal termasuk budaya harus mampu berdampingan dengan teknologi. Melihat surutnya budaya Mesatua di Bali membuat tradisi Mesatua dalam masyarakat Bali seakan hampir punah. Hal ini dapat membuat suatu kemungkinan hilangnya budaya tradisonal yang memiliki nilai-nilai budaya yang sangat penting bagi anak-anak. Namun, dengan adanya upaya pelestarian budaya melalui pemanfaatan teknologi media digital. Mesatua Bali yang mulanya dikenal sebagai budaya lisan sekarang mulai dikenal sebagai budaya gambar yang di tuangkan kedalam media digital dengan cerita bergambar yang menarik bagi anak-anak.

Budaya Bali memang menarik dan unik. Selain merupakan salah satu ikon kebanggaan Indonesia yang telah mendatangkan banyak wisatawan dan devisa bagi Indonesia karena lingkungan alam dan budayanya (Pratama,2019). Bali juga sebagai lokus kehidupan yang unik memiliki banyak cerita yang dinamis sebagai pola kehidupan yang humanis-religius. Keunikan budaya Bali dilandasi oleh nilai-nilai yang bersumber pada ajaran agama Hindu.

Kebudayaan Bali sesungguhnya merupakan ekspresi dari hubungan interaksi orang Bali dengan lingkungannya. Dalam kosmologi orang Bali, lingkungan dibedakan atas dua macam, yakni lingkungan sekala (nyata) dan lingkungan niskala (tidak nyata). Lingkungan sekala meliputi lingkungan sosial (masyarakat) dan lingkungan fisik (alam sekitarnya). Sedangkan lingkungan niskala merupakan lingkungan spiritual yang dihuni oleh kekuatan-kekuatan supernatural atau adikodrati yang diyakini dapat menimbulkan pengaruh positif maupun negatif terhadap kehidupan manusia(Pratama,2019).

Ekspresi dari interaksi antara orang Bali dengan lingkungan spiritual (niskala) melahirkan sistem religi lokal atau "agama Bali" yang di dalamnya mencakup emosi atau sentimen keagamaan, konsepsi tentang kekuatan-kekuatan dan mahluk-mahluk gaib, upacara ritual keagamaan, fasilitas keagamaan, kelompok atau komunitas keagamaan. Dalam perkembangan selanjutnya keberadaan religi lokal tersebut bercampur dengan unsur-unsur agama Hindu yang disebabkan oleh adanya proses perjumpaan kebudayaan pada masa lampau.

Dalam transformasi kebudayaan Bali, I Wayan Geriya mengungkapkan, perubahan bentuk kebudayaan berimplikasikan dan mempunyai aspek yang sangat besar dan luas. Cakupan itu tidak saja berupa dimensi, cara, jaringan relasi fungsional, juga struktur yang terkait dengan pembesaran skala secara horizontal dan vertikal, tanpa meninggalkan esensi jati diri kebudayaan yang berkelanjutan. Lebih lanjut dianalogikan seperti kupukupu dengan proses transformasi biologisnya, dari perubahan telur menjadi ulat, kepompong hingga menjadi kupu-kupu yang dapat terbang bebas karena ada perubahan bentuk dan fungsi, namun tetap dalam esensi spesiesnya, tidak berubah ke spesies burung maupun yang lainnya. (Geriya, 2000:109).

Kronologis kebudayaan Bali, ditinjau dari persepektif historis, dapat dirunut menjadi tiga tradisi pokok, yaitu tradisi kecil, tradisi besar, dan modern. Tradisi kecil yang dimaksud adalah kebudayaan yang berorientasikan Bali lokal dengan ciri-ciri tertatanya sistem pengairan oleh kelompok-kelompok organisasi nonformal yang disebut subak dan berternak dengan tujuan untuk keperluan upacara maupun memenuhi kebutuhan keluarga serta membuat barang-barang atau peralatan rumah dan sarana keagamaan. Dalam tradisi besar telah terjadinya akulturasi antara kebudayaan Bali lokal dengan kebudayaan Hindu Jawa yang melahirkan kebudayaan Bali tradisi. Ciri-cirinya adalah adanya kekuasaan terpusat lewat konsep Dewa Raja. Raja dianggap sebagai inkarnasi Dewa dengan segala kelebihannya dibandingkan rakyat kebanyakan (Geriya,2000:2).

Sejarah panjang seni Nusantara Indonesia, Bali memiliki kedudukan tersendiri. Latar Belakang tradisional yang kuat dan kemampuan seni yang khas dari masyrakatnya menyebabkan bahwa perkembangan seni di Bali berbeda dengan perkembangan seni modern di Jawa. Sebaliknya, seni Bali tidak mempengaruhi seni Jawa dan bagian Indonesia lainnya. (Soemantri, 2002:7).

Perubahan gaya dalam seni Bali dimulai dengan pengenalan kertas gambar pada akhir abad ke-19 yang mendorong percobaan-percobaan dengan ruang dan bentuk nyata. Pada tahun 1930-an, perbaruan dengan para pelukis ekspatriat yang ahli dalam gaya naturalis romantis mendorong para pelukis Bali melukis dengan cara lebih realis. Namun demikian, pengayoman yang diberikan oleh para seniman asing ini juga berarti bahwa lukisan-lukisan yang dihasilkan disesuaikan dengan citarasa Barat. Seni modern di Bali berkembang sedikit banyak terlepas dari perkembangan diwilayah lain Indonesia dan menghasilkan banyak ragam gaya. Sebelum gelombang Barat datang, lukisan Bali dipersembahkan untuk kerperluan keagamaan dengan gaya wayang tradisional (Soemantri, 2002:116).

Sejarah seni rupa Bali telah berjalan cukup panjang dan mengalami berbagai perubahan. Perkembangan itu sebagai akibat terjadinya proses interaksi internal dan eksternal, yang sampai sekarang berkembang semakin kompleks. Secara eksternal diakibatkan oleh masuknya orang-orang dan kebudayaan asing, setelah Bali dinyatakan sebagai pusat pariwisata. Pariwisata telah dipercaya mampu mendorong kehidupan kesenian maupun unsur kebudayaan lainnya. Secara internal mampu mendorong lahirnya kreativitas seni bagi para seniman maupun perupa Bali.

Dari uraian di atas jelas kiranya bahwa budaya dapat diminati oleh seseorang berdasarkan pengetahuan, pengalaman, dan juga nilai yang mereka dapat dan terapkan pada lingkungannya. Pada kajian penelitian ini, penulis berusaha memfokuskan diri untuk meneliti dan 
menganalisa perubahan budaya Mesatua Bali dalam upaya pelestariannya. Untuk memenuhi kebutuhan data yang digunakan sebagai bahan penelitian ini digunakan metode penelitian kualitatif deskriptif untuk mendeskripsikan fenomena perubahan yang terjadi dengan didasari atas pengumpulan data yang di lakukan melalui observasi, dokumentasi serta studi pustaka. Mesatua Bali merupakan tradisi mendongeng yang dilakukan para orang tua pada anaknya. Hal ini membuat hilangnya budaya tradisonal yang memiliki nilai-nilai budaya (Pratama,2020).

Melestarikan budaya bukan hanya sekedar kepentingan dan tanggung jawab pemerintah, tetapi juga kewajiban semua lapisan masyarakat di lingkungan. Dalam upaya melestarikan budaya. (Pratama,2020). Bali dikenal sebagai salah satu provinsi di Indonesia dengan ragam kekayaan budaya yang selalu dilestarikan dan diturunkan dari generasi ke generasi. Namun dalam upaya merubah pola pikir masyarakat Bali agar lebih bertanggung jawab dan merasa memiliki warisan budaya Mesatua Bali, tentunya bukan hal yang mudah. Membutuhkan pendekatan yang berbeda dan harus mampu menarik minat masyarakat untuk melihat dan memahami dampak yang disebabkan oleh fenomena suatu budaya.

\section{Rumusan Masalah}

1. Apakah aspek-aspek yang mendorong perubahan budaya Mesatua Bali.

2. Apa yang berubah, apa yang tetap (dipertahankan), apa yang hilang, dan apa yang baru, dari fenomena perubahan budaya Mesatua Bali.

\section{Tujuan Penelitian}

1. Mengetahui faktor-faktor yang menyebabkan fenomena perubahan budaya Mesatua Bali.

2. Manganalisis apa yang berubah, apa yang tetap (dipertahankan), apa yanghilang, apa yang baru pada fenomena perubahan budaya Mesatua Bali.

\section{Pembahasan}

Dalam perkembangannya budaya Mesatua Bali dikenalkan melalui karya sastra berupa buku. Menurut Ni Nyoman Karmini (2017), Dalam kehidupan bermasyarakat terdapat asas kekeluargaan yang kuat, karena pada dasarnya manusia merupakan makhluk pribadi dan sekaligus makhluk sosial. Merupakan fakta juga, bahwa dewasa ini krisis moral dan akhlak melanda kehidupan masyarakat. Salah perkataan, sengaja maupun tidak sengaja menimbulkan permasalahan yang panjang. Hal ini sebenarnya dapat diatasi dengan pengendalian diri dan pembinaan watak walaupun butuh waktu. Untuk pembinaan watak salah satunya dapat dilakukan atau diterapkan lewat pembelajaran sastra, baik di sekolah maupun di rumah. Artinya, lewat materi sastra ajaran moral disampaikan secara jujur dan benar, karena sebuah karya sastra bersumber dari kenyataan-kenyataan yang hidup dalam masyarakat (realitas-objektif).

Karya sastra tidak hanya mengungkapkan realitas objektif melainkan juga mengungkapkan nilai-nilai.
Karya sastra bukan semata-mata tiruan dari alam (imitation of nature) atau tiruan dari hidup (imitation of life), tetapi juga merupakan penafsiran-penafsiran tentang alam dan kehidupan itu (interpretation of life). Karya sastra mengungkapkan masalah-masalah manusia dan kemanusiaan, tentang makna hidup dan kehidupan. Sastra melukiskan penderitaan-penderitaan manusia, perjuangannya, kasih sayangnya, nafsunya, dan segala sesuatu yang dialaminya. Lewat karya sastra, pengarang ingin menampilkan nilai-nilai yang lebih tinggi dan lebih agung. Lewat karya sastra dapat menafsirkan tentang makna hidup dan hakikat hidup (Karmini, 2011:2).

\section{A. Mesatua Bali Lisan}

Satua merupakan salah satu cerita rakyat lisan di Bali. Bila dikaitkan dengan ilmu folklor, satua termasuk dalam kelompok folklore lisan. Secara definitif, folklor adalah sebagian kebudayaan suatu kolektif, yang tersebar dan diwariskan secara turun temurun. Folklor dapat digolongkan menjadi tiga kelompok yaitu folklor lisan, folklor sebagian lisan, folklor bukan lisan. Folklor lisan adalah folklor yang bentuknya memang murni lisan, yang termasuk dalam bentuk ini yaitu bahasa rakyat, ungkapan tradisional, pertanyaan tradisional, sajak dan puisi rakyat, cerita prosa rakyat, dan nyanyian rakyat.

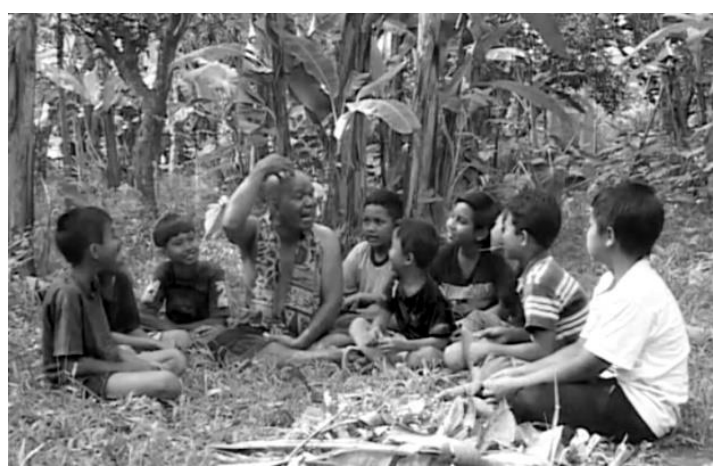

Gambar 1. Pekak Botak Mesatua Bali (foto: Pratama, 2018)

Folklor sebagian lisan yaitu folklore yang merupakan campuran dari unsur lisan dan unsur bukan lisan, yang termasuk dalam bentuk ini yaitu kepercayaan rakyat dan permainan rakyat. Folklor bukan lisan yaitu folklor yang bentuknya bukan lisan walaupun2 cara pembuatannya dilakukan secara lisan. Folklor bukan lisan dibagi menjadi dua kelompok yaitu material dan non-material. Yang termasuk material yaitu arsitektur rakyat dan kerajinan tangan rakyat, serta yang termasuk dalam non- material yaitu gerak isyarat tradisional, bunyi isyarat seperti kulkul dan gamelan (Dananjaya, 2007: 21 22). Sehingga satua maupun budaya Mesatu Bali dapat digolongkan kedalam kelompok folklor lisan.

\section{B. Mesatua Bali Sastra Tulisan (Buku}

Dalam perkembangan budaya Mesatua Bali dalam karya sastra, seorang penulis buku Satua-Satua Bali pada tahun 1993 bernama INengah Tinggen yang juga merupakan Dosen Luar Biasa di PGSD - STKIP Negeri Singaraja, mengumpulkan cerita-cerita rakyat Bali 
(satua) dengan tujuan mengenalkan dan menyebarluaskan cerita satua Bali, disamping ingin memetik isi yang sebagian besar mengacu kepada pendidikan dan juga sebagai hiburan, terutama bagi anak-anak. Bahan cerita tersebut sebagia besar didapatkan dari Gedung Kirtia Singaraja, hanya saja ejaanya telah dirubah sesuai dengan "ejaan Bahasa Daerah Bali yang disempurnakan (huruf latin).

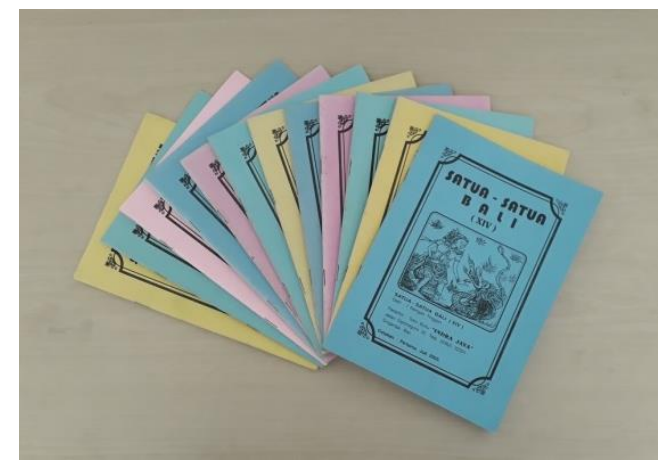

Gambar 2. Buku Satua Bali -I Nengah Tinggen (foto: Pratama, 2018)

Kumpulan cerita pada Buku Satua-Satua Bali Karangan I Nengah Tinggen di terbitkan oleh Toko Buku "INDRA JAYA" Singaraja dalam 15 jilid. Diterbitkan mulai pada tahun (1993-2002.) Harapan dengan tersebarnya buku Satua Bali tersebut dapat di manfaatkan dan nikmati oleh para siswa maupun mahasiswa dan tidak merasakan kesulitan dalam mendapatkan bahanbahan cerita yang pada saat itu merupakan tugas sekolah dari guru-guru pengajar Bahasa daerah Bali.

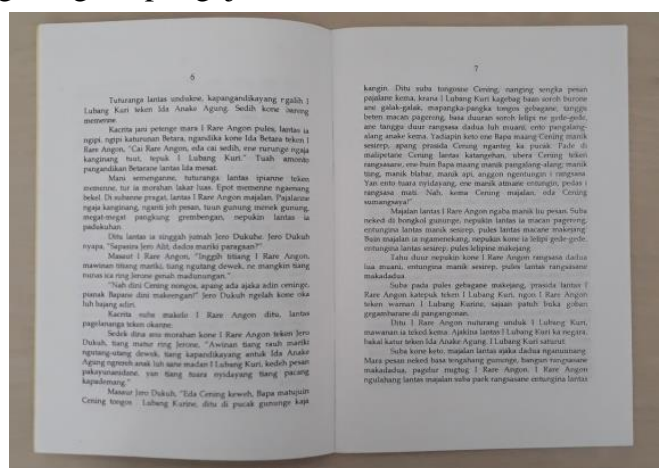

Gambar 3. Tampilan Isi Buku Satua Bali- I. N.Tinggen (foto: Pratama, 2018)

\section{Mesatua Bali Bergambar (Visual)}

Surutnya budaya Mesatua di masyarakat membuat tradisi Mesatua di masyarakat Bali hampir punah. Hal ini patut disesalkan. Salah satu penyebabnya adalah merebaknya arus informasi dari berbagai penjuru dunia melalui media elektronika seperti televisi. Hampir setiap hari, baik pagi, siang, sore maupun malam hari, televisi menyuguhkan dongeng berupa film kartun. Cerita dongeng modern tersebut yang kebanyakan film impor sangat digandrungi anak-anak. Dibandingkan dongeng televisi, Mesatua secara langsung jauh lebih efektif dalam mendidik anak-anak sejak dini. Mesatua memiliki nilai-nilai kebaikan seperti kejujuran, kesetiaan kerja keras, hingga sopan santun. Nilai-nilai ini akan dapat diserap anak-anak kalau Mesatua tersebut dapat disampaikan dengan baik dan benar. Film kartun yang ditayangkan di televisi tidak seperti ibu dan anak yang bisa berkomunikasi secara langsung dengan anak atau cucunya. Pesawat televisi hanya bisa bercerita satu arah dan bersifat kaku, sehingga nilai-nilai dongeng tersebut tidak dapat diterima oleh si anak.

Membicarakan masalah rupa, dalam hal ini merupakan bentuk atau wujud itu sendiri yang bisa dilihat secara nyata (visualisasi bentuk), bentuk dalam seni rupa disebut juga bahasa rupa, rupa bercerita, rupa yang dimaksud adalah suatu bentuk atau wujud suatu benda, abik benda yang berwujud secara dwimatra maupun trimatra, sehingga pada bahasa rupa dwimatra dan bahasa rupa trimatra tampak wujudnya. Suatu Karya rupa yang berbentuk gambar merupakan visualisasi bentuk yang kasat mata. Gambar yang tampak pada suatu bidang yang relatif datar biasanya berupa sketsa, gambar, lukisan, foto, karya grafis, relief, layar lebar, layar kca (TV), layar monitor (Komputer) dan sebagainya (Tabrani, 2000:1).

Menurut Made Taro, seorang penulis yang juga merupakan Maestro Seni Tradisi Lisan di Bali menyatakan bahwa, penemuan teknologi modern yang serba canggih, efektif, efisiem dam praktis sangat mempengaruhi pola hidup manusia yang menuntut kesejahteraan lahir batin. Masyarakat hidup dalam situasi dan suasa bersaing dan berpacu dengan waktu. Keadaan seperti itu mengancam hilangnya tradisi budaya Mesatua (mendongeng) dirumah tangga yang diwaranai suasana rekreaktif, komunikasi dua arah, dan hubungan akrab. Diakui, tradisi budaya Mesatua Bali (mendongeng) yang sarat akan nilai moral dan pendidikan karakter itu masih dibutuhkan (Pratama.2015).

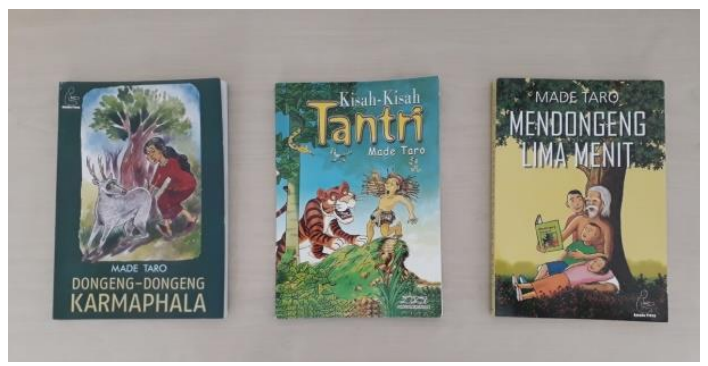

Gambar 4. Buku Satua Bali Karangan Made Taro (foto: Pratama, 2018)

Beberapa buku yang dituliskan oleh Made Taro diterbitkan pada tahun (2006-2017), buku-buku ini terdiri dari cerita Mesatua Bali yang sudah disadur kedalam Bahasa Indonesia. Didalam buku ini pun sudah dilengkapi dengan berbagai ilustrasi di masing-masing judulnya. Cerita yang terkumpul dalam buku ini merupakan hasil olahan yang memerlukan cukup waktu. Made Taro mulai dengan mempublikasikan cerita tersebut melalui tabloid "Tokoh" dan "Lintang" yang terbit di Denpasar.

Adapun buku Satua Bali lainnya yang merupakan karangan dari I.N.K Suparta dengan judul "Kambing 
Takutin Macan”. Pada satwa tersebut selain berisikan naskah cerita juga terdapat ilustrasi dari satwa tersebut. Digambarkan 3 tokoh yaitu Kambing, Macan, dan Kera dalam cerita pada satu ilustrasi di muat dalam satu halaman penuh.

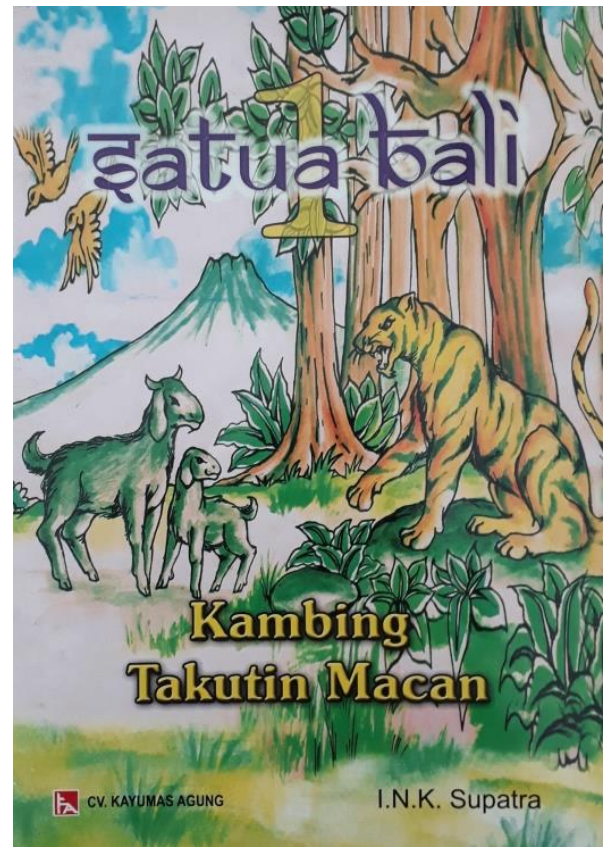

Gambar 5. Sampul pada Buku Satua Bali "Kambing Takutin Macan” Karangan I.N.K. Suparta (foto: Pratama, 2018)
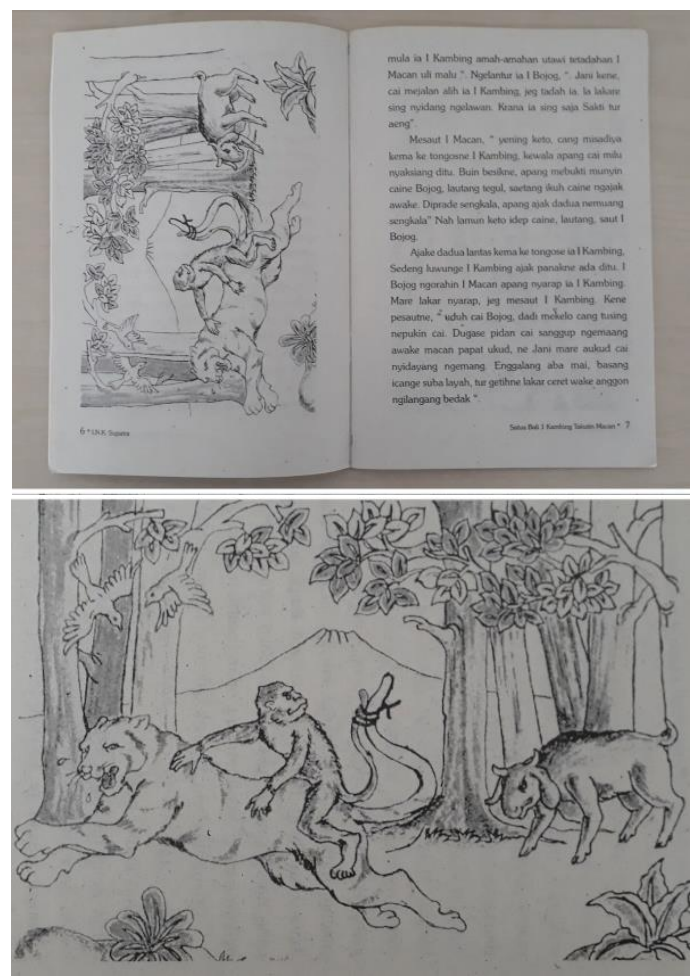

Gambar 6. Ilustrasi pada Isi Buku Satua Bali “Kambing Takutin Macan” Karangan I.N.K. Suparta (foto: Pratama, 2018)

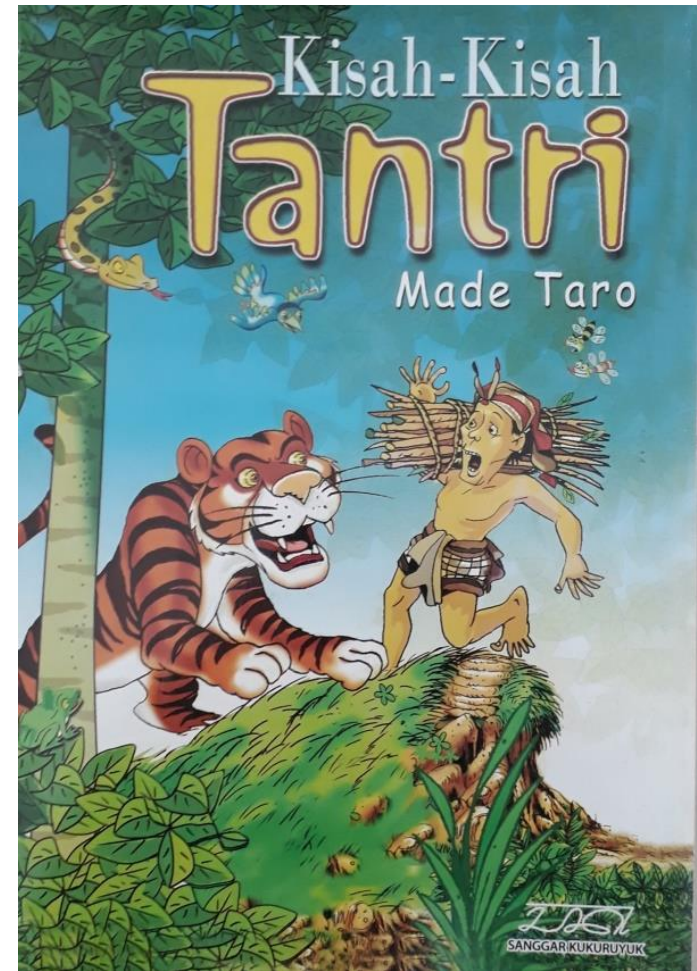

Gambar 7. Sampul pada Buku Kisah-Kisah Tantri "Kambing Pemberani” Karangan Made Taro (foto: Pratama, 2018)
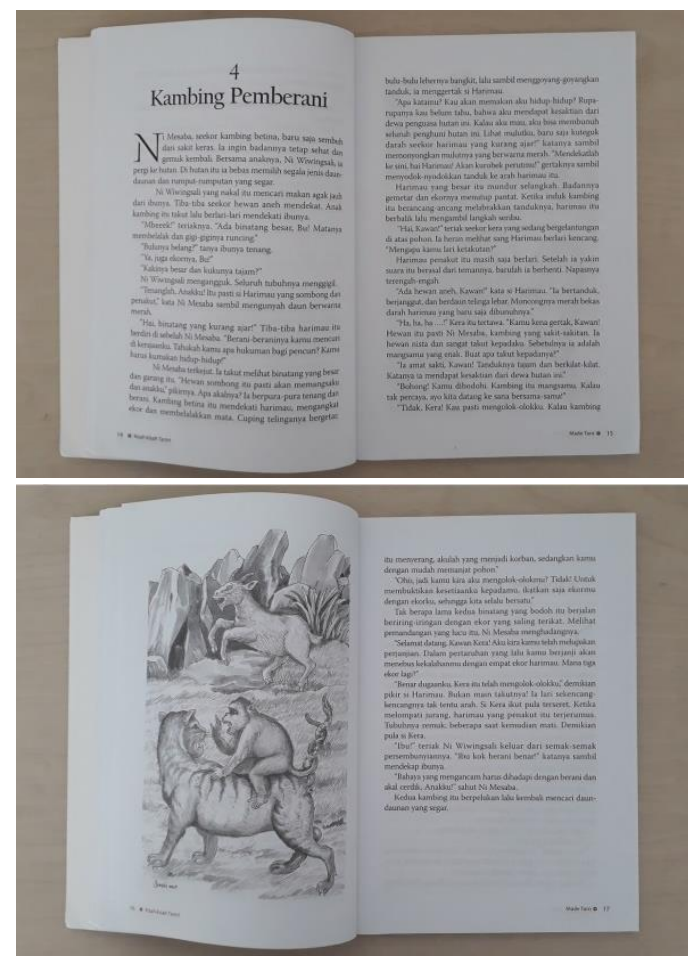

Gambar 8. Ilustrasi Buku Kisah-Kisah Tantri "Kambing Pemberani” Karangan Made Taro (foto: Pratama, 2018)

Setelah diketahui identifikasi dari objek penelitian, yaitu periode perkembangan budaya Mesatua Bali dalam pelestariannya, yang dimulai dari periode pertama (lisan), budaya Mesatua Bali periode kedua (sastra 
buku), Mesatua Bali periode ketiga (visual), kemudian data hasil dari identifikasi tersebut akan dianalisis sebagai data komparasi pada tabel selanjutnya, menggunakan 4 (empat) indicator / aspek perubahan berdasarkan waktu, ditampilkan dalam tabel berikut:

Tabel.1. Aspek fenomena perubahan budaya Mesatua Bali

\begin{tabular}{|c|c|c|c|}
\hline & LISAN & TULISAN & VISUAL \\
\hline $\begin{array}{c}\text { Apa } \\
\text { Yang } \\
\text { Baru }\end{array}$ & $\begin{array}{l}\text { Mesatua } \\
\text { Bali } \\
\text { sebagai } \\
\text { budaya } \\
\text { lisan yang } \\
\text { disampaika } \\
\text { n dengan } \\
\text { narasi dan } \\
\text { tembang. }\end{array}$ & $\begin{array}{l}\text { Mesatua } \\
\text { Bali } \\
\text { sebagai } \\
\text { karya sastra } \\
\text { yang } \\
\text { dimuat } \\
\text { kedalam } \\
\text { media cetak } \\
\text { berupa } \\
\text { buku. }\end{array}$ & $\begin{array}{l}\text { Mesatua } \\
\text { Bali } \\
\text { disajikan } \\
\text { dalam } \\
\text { bentuk } \\
\text { ilustrasi } \\
\text { bergamba } \\
\text { r. }\end{array}$ \\
\hline $\begin{array}{c}\text { Apa } \\
\text { Yang } \\
\text { Berub } \\
\text { ah }\end{array}$ & $\begin{array}{l}\text { Orang tua } \\
\text { sebagai } \\
\text { pelaku } \\
\text { utama } \\
\text { dalam } \\
\text { Mesatua } \\
\text { Bali } \\
\text { dilingkunga } \\
\text { n rumah. }\end{array}$ & $\begin{array}{l}\text { Para Guru } \\
\text { di sekolah } \\
\text { menjadi } \\
\text { pelaku } \\
\text { utama } \\
\text { dalam } \\
\text { belajar \& } \\
\text { membacaka } \\
\text { n buku } \\
\text { satua Bali. }\end{array}$ & $\begin{array}{l}\text { Setiap } \\
\text { satua } \\
\text { (dongeng) } \\
\text { sudah } \\
\text { didukung } \\
\text { dengan } \\
\text { ilustrasi } \\
\text { bergamba } \\
\text { r. }\end{array}$ \\
\hline $\begin{array}{c}\text { Apa } \\
\text { yang } \\
\text { hilan } \\
\text { g }\end{array}$ & $\begin{array}{l}\text { Interaksi } \\
\text { orang tua } \\
\text { bersama } \\
\text { anak-anak } \\
\text { dalam } \\
\text { Mesatua } \\
\text { yang } \\
\text { menumbuh } \\
\text { kan } \\
\text { imajinasi } \\
\text { anak. }\end{array}$ & $\begin{array}{l}\text { Anak-anak } \\
\text { jarang } \\
\text { dapat } \\
\text { melakukan } \\
\text { aktivitas } \\
\text { Mesatua } \\
\text { Bali di } \\
\text { rumah. }\end{array}$ & $\begin{array}{l}\text { Berkurang } \\
\text { nya } \\
\text { Imajinasi } \\
\text { anak } \\
\text { ataupun } \\
\text { target, } \\
\text { karena } \\
\text { sudah } \\
\text { disajikan } \\
\text { gambar. }\end{array}$ \\
\hline $\begin{array}{c}\text { Apa } \\
\text { Yang } \\
\text { Tetap }\end{array}$ & $\begin{array}{l}\text { Anak-anak } \\
\text { sebagai } \\
\text { target } \\
\text { utama } \\
\text { dalam } \\
\text { Mesatua } \\
\text { Bali. }\end{array}$ & $\begin{array}{l}\text { Anak-anak } \\
\text { sebagai } \\
\text { target } \\
\text { utama } \\
\text { dalam } \\
\text { Mesatua } \\
\text { Bali. }\end{array}$ & $\begin{array}{l}\text { Anak- } \\
\text { anak } \\
\text { sebagai } \\
\text { target } \\
\text { utama } \\
\text { dalam } \\
\text { Mesatua } \\
\text { Bali. } \\
\end{array}$ \\
\hline
\end{tabular}

Dapat dilihat pada tabel diatas, bahwa dalam perkembangan budaya Mesatua Bali, mulai dari lisa, tulisan, hingga visual mengalami fenomenas perubahan di setiao periodenya. Dimana, dari masing-masing periode tersebut terdapat beberapa aspek yang tetap, baru, berubah, dan bahkan hilang.

\section{Kesimpulan dan Saran}

\section{A. Kesimpulan}

Belajar dari sejarah dan lingkungan serta menjawab yang dirasakan terhadap budaya Mesatua Bali yang teridentifikasi, serta mengalami pasang surut kontestasi budaya sebagai dampak fenomena budaya. Upaya pelestarian yang berdampak terhadap perubagan tidaklah mudah, karena harus berhadapan dengan berbagai stigma kultural yang disampirkan. Di sinilah masyarakat Bali harus menunjukan kemampuannya untuk menegosiasikan kembali posisi budaya Mestua Bali, melakukan resistensi dengan membangkitkan kesadaran seluruh masyarakatnya.

Sejarah seni rupa Bali telah berjalan cukup panjang dan mengalami berbagai perubahan. Perkembangan itu sebagai akibat terjadinya proses interaksi internal dan eksternal, yang sampai sekarang berkembang semakin kompleks. Secara eksternal diakibatkan oleh masuknya orang-orang dan kebudayaan asing, setelah Bali dinyatakan sebagai pusat pariwisata. Pariwisata telah dipercaya mampu mendorong kehidupan kesenian maupun unsur kebudayaan lainnya. Secara internal mampu mendorong lahirnya kreativitas seni bagi para seniman maupun perupa Bali.

Langkah pelestarian budaya Mesatua Bali pada dasarnya merupakan fenomena perubahan budaya dalam konteksnya yang lama menjadi tradisi dengan konteks kekinian. Dengan Kata lain merupakan tindakan menghidupkan kembali suatu hal yang sebelumnya kurang berdaya menjadi penting, atau beberapa bagian dipertahankan dan lainnya diaktualisasikan sehingga berbeda dari wujud lamanya.

\section{B. Saran}

Hal terpenting dalam memahami keberagaman budaya sebagai produksi dan reproduksi ada dalam prosesnya, yaitu formalisasi, ritualisasi, dan pengkarakteran yang mengacu pada masa lampau. Mungkin, bagi generasi tua, pengembangkan suatu budaya lokal tidak serta merta dapat diterima, sehingga proses adaptasi masih tetap berlangsung, karena membangkitkan nilai-nilai budaya Mesatua Bali adalah respon terhadap dinamika keberagaman budaya yang berkembang, serta bagian proses reformulasi identitas diri dan strategi menghadapi perubahan yang bernilai filosofis dan historis. Dimana di Bali terkenal dengan gaya lukisnya yang khas, namun jika dilihat pada perkembanganya saat ini sangat berbeda. Hal ini terlihat jelas illustrator maupun desainer masa kini sebagai pelaku (maker) seharusnya lebih mampu untuk menghasilkan karya-karya ilustrasi dengan gaya gambar khas Bali yang memiliki konsep estetika Bali. 


\section{Daftar Pustaka}

Danandjaja, James. 2007. Folklor Indonesia : Ilmu Gosip, dongeng, dan lain-lain. Jakarta : Grafiti.

Geriya. I Wayan. 2000. Transformasi Kebudayaan Bali Memasuki Abad XXI.

Karmini, Ni Karmini. 2011. Teori Pengkajian Prosa Fiksi dan Drama. Saraswati Institut Press Pustaka Larasan: Denpasar, Bali.

Pratama, I. TA: Penciptaan Buku Pop-up Mesatua Bali Berjudul" I Lubdhaka" Dengan Teknik Pull Tab Sebagai Upaya Pelestarian Budaya Tradisional. Diss. Institut Bisnis dan Informatika Stikom Surabaya, 2015.

Pratama, I. Gede Yudha. "Aesthetics Study of Mesatua Bali Culture in Digital Media." International Conference on Business, Economic, Social Science and Humanities (ICOBEST 2018). Atlantis Press, $2018 . \quad$ (https://www.atlantispress.com/proceedings/icobest-18/25906821, accessed date 28 May 2020).

Pratama, I. Gede Yudha. "REVITALIZATION OF MESATUA BALI CULTURE THROUGH THE DIGITAL MEDIA." ARTic 3 (2019): 135-153. (https://search.unikom.ac.id/index.php/artic/article/v iew/2521, accessed date 14 Juli 2020).

Pratama, I. Revitalisasi Budaya Mesatua Bali Melalui Media Digital (Kajian Desain Visual). Diss. Universitas Komputer Indonesia, 2019, [pdf], (https://elibrary.unikom.ac.id/id/eprint/1284/8/UNIK OM_I\%20Gede\%20Yudha\%20Pratama_BAB\%20II \%20TINJAUAN\%20PUSTAKA.pdf accessed date 14 Juli 2020).

Pratama, I. Gede Yudha. "EFEKTIVITAS MEDIA DIGITAL DALAM PERKEMBANGAN BUDAYA MESATUA BALI." SENADA (Seminar Nasional Desain Dan Arsitektur). Vol. 3. 2020. (https://eprosiding.stdbali.ac.id/index.php/senada/article/view/265).

Soemantri, Hilda. 2002. INDONESIAN HERITAGE: Seni Rupa. Jakarta: Buku Antar Bangsa.

Tabrani, Primadi. 2012. BAHASA RUPA. Bandung: Penerbit Kelir. 